\title{
Congress of neurological surgeons systematic review and evidence-based clinical practice parameter guidelines for the treatment of adults with newly diagnosed glioblastoma: Introduction and Methods
}

\author{
Jeffrey J. Olson ${ }^{1}\left[\right.$. Timothy C. Ryken ${ }^{2}$
}

Received: 12 July 2020 / Accepted: 7 August 2020

(c) Springer Science+Business Media, LLC, part of Springer Nature 2020

\begin{abstract}
Purpose This is an update of the evidence-based guideline for management of newly diagnosed glioblastomas sponsored by the American Association of Neurological Surgeons (AANS) and Congress of Neurological Surgeons (CNS) initially published in 2008. The objective is to update evidence-based management of newly diagnosed glioblastomas over all commonly used diagnostic and treatment modalities in regularly encountered clinical situations.

Methods A multidisciplinary writing group was assembled to create documents related to imaging, cytoreductive surgery, neuropathology, radiation therapy, chemotherapy and emerging developments. Questions from the prior set of guidelines, and new and modified questions were used to guide a search of the scientific literature since the last guideline search was completed in June 2005. Citations were screened, classified and used as evidence to create recommendations addressing the questions in a manner that was directly linked to this evidence.

Results The sixteen writers produced 34 questions resulting in eight Level I recommendations, eleven Level II recommendations, and 27 Level II recommendations across all the topics. In some instances, insufficient data was available to answer all or part of a question and this is stated and explained.

Conclusions This series of guidelines is based upon relevant evidence in the literature related to the management of newly diagnosed glioblastomas. They set a benchmark for the management of this disease while highlighting key areas of weakness in our knowledge and suggest directions for future basic and clinical research to improve evidence quality and recommendation strength.
\end{abstract}

Keywords Glioblastoma · Therapy · Guidelines

\section{Introduction}

\section{Background and rationale}

Sponsored by the American Association of Neurological Surgeons and Congress of Neurological Surgeons Joint Section on Tumors.

Reviewed for evidence-based integrity and endorsed by the American Association of Neurological Surgeons and Congress of Neurological Surgeons.

Jeffrey J. Olson

jolson@emory.edu

1 Department of Neurosurgery, Emory University School of Medicine, Atlanta, GA, USA

2 Section of Neurosurgery, Dartmouth University, Hanover, $\mathrm{NH}, \mathrm{USA}$
In 2008 guidelines on the management of newly diagnosed glioblastoma were published and endorsed by the American Association of Neurological Surgeons (AANS) and Congress of Neurological Surgeons (CNS) [1-6]. A component of that set of guidelines was recognition that updates would eventually be necessary so as to allow the recommendations to be modified to stay abreast of advances in the care and management of newly diagnosed glioblastomas. This document, as well as the set of companion documents on the various facets of newly diagnosed glioblastoma management, are the action taken in response to that recognition. 
Glioblastoma remains the most common primary malignant glioma and when it occurs it often afflicts individuals during the most productive years of their lives [7-10]. Reflective of it's serious nature, the median survival is 14-15 months [11-13]. Key reasons behind this poor prognosis may include the tumor's underlying molecular heterogeneity brought to light by The Cancer Genome Atlas, and it's rapid and infiltrative growth pattern [13-16]. The standard treatment for newly diagnosed glioblastomas remains some form of surgery, radiation therapy and chemotherapy. However, since the last set of guidelines was published in 2008 new knowledge has emerged affecting the management of newly diagnosed glioblastoma. The new World Health Organization classification of central nervous system tumors has provided an important step toward connecting information from molecular markers with prognostic and therapeutic information [10, 17, 18] Additionally, the FDA has approved the addition of tumor treating fields to adjuvant temozolomide after radiation with concurrent temozolomide in newly diagnosed glioblastoma [19]. The initial promise of bevacizumab has been tempered by experience over a broader range of clinical circumstances [20]. Recognition that antiangiogenic therapy may be individually guided with properly designed MRI measurement of the effect of these agents on a given tumor will allow these treatments to be delivered to those individuals most likely to benefit from them.[21]. Encouragingly, considerable research effort is currently being directed toward refining molecular targeted agents [10]. On another scientifically promising front research on immunotherapies in the form of vaccinations and check point inhibitors has picked up pace since the last set of guidelines were published [22-25].

These updated guidelines include sections similar to those previously published, including imaging, cytoreductive surgery, neuropathology, radiation therapy, chemotherapy and targeted therapy. The methods and style used here are adapted from and similar to other guidelines projects produced by the AANS and CNS. This coherence and repetitive nature is intentionally used for the purposes of reproducibility and streamlining the administration of their creation. Each section was developed with recognition of the Preferred Reporting Items for Systematic Reviews and Meta-Analyses (PRISMA) checklist items [26]. The manner in which the points on the PRISMA checklist are addressed varies from section to section depending on the nature of the information available.

\section{Objectives}

Recognizing the important health impact of newly diagnosed glioblastoma along with the lack of consensus across various treatment options, the Joint Tumor Section of the CNS and AANS recommended that evidence-based guidelines be developed for the diagnosis, management, and treatment of patients suffering from this malady. Thus, the objectives of these guidelines are to establish the best evidence-based management of newly diagnosed glioblastoma in terms of initial imaging for diagnosis, use of surgical techniques, assessment of tumor pathology, and administration of radiation therapy, cytotoxic chemotherapy and targeted therapy.

\section{Methods}

\section{Process used in development of these guidelines}

Having identified the topical objectives, the Guidelines Committee of the AANS/CNS Joint Tumor Section then recruited experts in the field from each of the parent organizations as lead authors of each section. These authors, in turn, recruited experts in non-neurosurgical specialties relevant to the field of management and therapy chosen (Table 1). The authors were provided with training on the method of guideline development as used in this guideline set, utilizing stepwise written instructions and then providing direct guidance as needed for each writer. The senior authors then worked with the writers on a systematic basis to confirm that the methods were followed as the literature was collected and assessed, and the documents developed. When the authors were approached and preliminarily agreed to participate, they were asked to complete a formal conflict of interest questionnaire confirming the appropriateness of their participation. The authors also agreed to report any new conflicts of interest that might develop during the writing process. The method of this evidence-based clinical practice parameter guideline has been written in a manner to be as transparent as possible using published assessment criteria [27].

\section{Strategy for searching the literature}

A literature search strategy that was the same as the original set of guidelines was undertaken to identify all citations relevant to the management of newly diagnosed glioblastomas. The PubMed $®$, MEDLINE $®$ and Embase $\AA$ electronic databases were searched with additional data being gleaned from the Cochrane Database of Systematic Reviews and Cochrane Central Register of Controlled Trials. The date range for the search was from July 1, 2005 to October 31, 2018 for questions that were unchanged from the guidelines published in 2010. For new questions or questions modified significantly from the 2010 publication, the date range for the searches was chosen to be January 1990 through October 31,2018 . Additionally, important articles from prior to this interval were reviewed and included if deemed to be critical evidence by the writing group for the topic. The search 
Table 1 Newly diagnosed glioblastoma guidelines authors

\begin{tabular}{ll}
\hline Guideline Author & Affiliation \\
\hline Alexa Bodman, MD & Austin Brain and Spine, Austin \\
Daniel J. Brat, MD, Ph.D & Neuropathology, Northwestern University, Chicago \\
Jorg Dietrich, MD, Ph.D & Neurology, Massachusetts General Hospital, Boston \\
Joseph Domino, MD, MPH & Neurosurgery, University of Kansas \\
Christopher Farrell, MD & Neurosurgery, Thomas Jefferson, Philadelphia \\
Sarah Fouke, MD & Neurosurgery, St. Luke's, St. Louis \\
Isabelle M. Germano, MD & Neurosurgery, Mount Sinai Medical Center, New York \\
Wen Jian, MD, Ph.D & Radiation Oncology, UT Southwestern, Dallas \\
Steven N. Kalkanis, MD & Neurosurgery, Henry Ford, Detroit \\
Betty Y. Kim, MD, Ph.D & Neurosurgery, MD Anderson, Houston \\
Paige Lundy, MD & Neurosurgery, University of Kansas \\
David J. McCracken, MD & Neurosurgery, Piedmont Hospital, Atlanta \\
Brian V. Nahed, MD, M.Sc & Neurosurgery, Massachusetts General Hospital, Boston \\
Jeffrey J. Olson & Neurosurgery, Emory University \\
David R. Ormond, MD & Neurosurgery, University of Colorado \\
Navid Redjal, MD & Neurosurgery, Capital Institute, Pennington \\
Timothy Ryken, MD & Neurosurgery, Dartmouth \\
Mairaj Sami, MD & Neurosurgery, University of Kansas \\
Wenyin Shi, MD & Radiation Oncology, Thomas Jefferson, Philadelphia \\
Jose E. Velazquez-Vega, MD & Neuropathology, Emory University, Atlanta \\
Mateo Ziu, MD & Neurosurgery, Inova Institute, Falls Church \\
\hline &
\end{tabular}

strategies used a combination of controlled vocabulary terms and text words. The specifics of the searches for a given topic are outlined in each respective guideline section. Reference lists of the publications chosen for full-text review were also screened for potentially relevant studies.

\section{Strategy for study selection}

The search of the bibliographic databases identified possibly relevant citations for a given topic and often these were large in number. The eligibility (inclusion/exclusion) criteria to screen the citations for each of the questions were determined ahead of time for each section by the respective writing group. These are documented in the individual clinical practice guideline sections in this series to assist the reader in understanding the development process. At least two authors evaluated the titles and abstracts using the inclusion and exclusion criteria with broad interpretation of the criteria being used initially to maximize the likelihood of capturing pertinent information. A third author, when needed, resolved cases of disagreement about pertinence. The full-text articles of the selected abstracts were then collected and the same process of applying the eligibility criteria was carried out again with the more detailed information available in the manuscripts. Articles that met the eligibility criteria were grouped according to the questions they addressed and used to create the evidence tables and results sections. Reasons for exclusion for papers were also documented to be able to discuss pertinent problem citations in the results sections as needed.

\section{Strategy for selection and grading the literature}

Studies that met the eligibility criteria were subject to more detailed scrutiny. One writer extracted their data and the extracted information was checked by one or more other reviewers. Evidence tables, reporting the extracted study information and evidence classification (by the methods noted in the text below and Tables 2, 3, 4, 5), were generated for all of the included studies. Evidence tables were created with the most recent data first and subsequent listings in retrograde chronological order. The table headings consisted of first author name and year, followed by a brief study description, chosen data class, and conclusion. The authors were directed to construct the data in the tables in a succinct and fact-filled manner to allow for rapid understanding of the literature entry by the readership. The literature in the evidence tables was expanded upon in the results section of each section to emphasize important points supporting its classification and contribution to recommendations. Additional information about the methods utilized in this systematic review can be found at https://www.cns.org/guidelines/ guideline-development-methodology.

Internal drafts of the tables and manuscripts were developed by sharing them between authors electronically, by telephone, and in person meetings. Summary and conclusion 
Table 2 AANS/CNS classification of evidence on therapeutic effectiveness and levels of recommendation

\begin{tabular}{|c|c|}
\hline \multicolumn{2}{|c|}{ Evidence classification } \\
\hline Class I & $\begin{array}{l}\text { Evidence provided by one or more well-designed randomized controlled clinical trials, including overview (meta-analyses) of } \\
\text { such trials }\end{array}$ \\
\hline Class II & Evidence provided by well-designed observational studies with concurrent controls (e.g. case control and cohort studies) \\
\hline Class III & Evidence provided by expert opinion, case series, case reports and studies with historical controls \\
\hline \multicolumn{2}{|c|}{ Levels of recommendation } \\
\hline Level I & $\begin{array}{l}\text { Generally accepted principles for patient management, which reflect a high degree of clinical certainty (usually this requires } \\
\text { class I evidence which directly addresses the clinical questions or overwhelming class II evidence when circumstances pre- } \\
\text { clude randomized clinical trials) }\end{array}$ \\
\hline Level II & $\begin{array}{l}\text { Recommendations for patient management which reflect clinical certainty (usually this requires class II evidence or a strong } \\
\text { consensus of class III evidence) }\end{array}$ \\
\hline Level III & $\begin{array}{l}\text { Other strategies for patient management for which the clinical utility is uncertain (inconclusive or conflicting evidence or } \\
\text { opinion) }\end{array}$ \\
\hline
\end{tabular}

Table 3 AANS/CNS classification of evidence on diagnosis and levels of recommendation

\begin{tabular}{ll}
\hline $\begin{array}{l}\text { Class I evidence } \\
\text { Level I recommendation }\end{array}$ & $\begin{array}{l}\text { Evidence provided by one or more well-designed clinical studies of a diverse population using a "gold standard" } \\
\text { reference test in a blinded evaluation appropriate for the diagnostic applications and enabling the assessment of } \\
\text { sensitivity, specificity, positive and negative predictive values, and, where applicable, likelihood ratios }\end{array}$ \\
\hline $\begin{array}{l}\text { Class II evidence } \\
\text { Level II recommendation }\end{array}$ & $\begin{array}{c}\text { Evidence provided by one or more well-designed clinical studies of a restricted population using a "gold standard" } \\
\text { reference test in a blinded evaluation appropriate for the diagnostic applications and enabling the assessment of } \\
\text { sensitivity, specificity, positive and negative predictive values, and, where applicable, likelihood ratios } \\
\text { Class III evidence } \\
\text { Eevel III recommendation } \\
\text { ficity, positive and negative predictive values, and, where applicable, likelihood ratios }\end{array}$ \\
\hline
\end{tabular}

Table 4 AANS/CNS classification of evidence on clinical assessment and levels of recommendation

\begin{tabular}{ll}
\hline $\begin{array}{l}\text { Class I evidence } \\
\text { Level I recommendation }\end{array}$ & $\begin{array}{l}\text { Evidence provided by one or more well-designed clinical studies in which interobserver and/or intraobserver } \\
\text { reliability is represented by a Kappa statistic } \geq 0.60\end{array}$ \\
\hline $\begin{array}{l}\text { Class II evidence } \\
\text { Level II recommendation }\end{array}$ & $\begin{array}{c}\text { Evidence provided by one or more well-designed clinical studies in which interobserver and/or intraobserver } \\
\text { reliability is represented by a Kappa statistic } \geq 0.40\end{array}$ \\
$\begin{array}{l}\text { Class III evidence } \\
\text { Level III recommendation }\end{array}$ & $\begin{array}{c}\text { Evidence provided by one or more well-designed clinical studies in which interobserver and/or intraobserver } \\
\text { reliability is represented by a Kappa statistic }<0.40\end{array}$ \\
\hline
\end{tabular}

statements were included for each section, with comments on key issues for future investigation being added where pertinent. When adequate data was presented in the manuscripts, the authors made an effort to measure the agreement between observations or observers beyond chance utilizing the kappa statistic.

\section{AANS/CNS evidence classes and levels of recommendations}

The evidence as classified was then used to create recommendations, the strength of which were graded, as mentioned before, according to the CNS Guideline Development Methodology (Tables 2, 3, 4, 5). The class of evidence assigned to each study (i.e., Class I, II, or III) was based on study design, study quality and identified bias.
The strength of the recommendations made (i.e., Level I, II, or III) was directly linked to the evidence classification and took into account aspects of study quality and whether or not the plan was accomplished, not just study design. For instance, in the paradigm for therapeutic maneuvers, evidence is classified into that which is derived from the strongest clinical studies (e.g., well-designed, randomized controlled trials), or Class I evidence. Class I evidence is used to support recommendations of the strongest type, defined as Level I recommendations, indicating a high degree of clinical certainty. Non-randomized cohort studies, randomized controlled trials with design flaws, and case-control studies (comparative studies with less strength) are designated as Class II evidence. These are used to support recommendations defined as Level II reflecting a moderate degree of clinical certainty. Other sources of information, including observational studies such as case series and expert opinion, 
Table 5 AANS/CNS classification of evidence on prognosis and levels of recommendation

\section{Class I evidence}

Level I recommendation

Class II evidence

Level II recommendation

Class III evidence

Level III recommendation

In order to evaluate papers addressing prognosis, five technical criteria are applied:

Was a well-defined representative sample of patients assembled at a common (usually early) point in the course of their disease?

Was patient follow-up sufficiently long and complete?

Were objective outcome criteria applied in a "blinded" fashion?

If subgroups with different prognoses were identified, was there adjustment for important prognostic factors?

If specific prognostic factors were identified, was there validation in an independent "test set" group of patients?

as well as randomized controlled trials with flaws so serious that the conclusions of the study are truly in doubt are considered Class III evidence and support Level III recommendations, reflecting unclear clinical certainty.

To restate, Class I evidence could be extrapolated to Level I recommendations or lower, Class II evidence could be extrapolated to Level II evidence or lower, and Class III evidence could only yield Level III recommendations. Specifically, the level of a recommendation made could be decreased, based on consensus input by the writing group, if there were methodological concerns regarding the studies that provided evidence for that particular recommendation. Additional information about the methods utilized in this systematic review can be found at https://www.cns.org/guide lines/guideline-development-methodology.

\section{Guideline panel consensus and approval process}

As previously mentioned, a multidisciplinary task force was created for each section based on author expertise, in order to address each of the disciplines and particular areas of therapy selected for these clinical guidelines. Each group was involved with literature selection, creation and editing of the evidence tables and results for their specific section and discipline. Using this information, the task force then drafted the recommendations in response to the questions formulated at the beginning of the process, culminating in the clinical practice guideline for their respective discipline. The draft guidelines were then circulated to the entire task force to allow for multidisciplinary feedback, discussion, and ultimately approval.

The completed evidence-based clinical practice guidelines for the management of newly diagnosed glioblastomas were presented to the Joint Guidelines Review Committee (JGRC) of the AANS/CNS for peer review. The reviewers for the JGRC were vetted by the Journal of Neuro-oncology for suitability and expertise to serve as reviewers for the purposes of publication in that journal also. The final product was then approved by the executive committees of both the AANS and CNS prior to publication in the Journal of Neuro-oncology.

Figure 1 provides an outline of the key steps in the process of developing these clinical practice guidelines.

\section{Discussion}

This series of guidelines documents was constructed to assess reasonably current and clinically relevant evidence for the management of newly diagnosed glioblastomas in order to set a benchmark for current knowledge on this topic and to highlight important key areas for future research. Only by designing future investigations in a high quality manner that recognizes and overcomes prior weaknesses noted in these guidelines will advancement toward a remedy of this disease be achieved. Secondarily, the suggestions provided are set forth for conscientious use by the practicing physician who must take into account all of the unique individual conditions in the therapy of a given person during their illness. The application of published guidelines information is an activity that results in strong and often polarized opinions. The guidelines presented in this current project are not meant to resolve these issues, and it is unlikely that any could accomplish such a goal. Fortunately, new research is constantly underway, and these guidelines are meant to be improved as this new evidence matures and is published. One will note guidance for that process in the 2011 Institute of Medicine (now the National Academy of Medicine) Clinical Practice Guideline Development Process. An important part of that document, called Standard 8, suggests timely updating of the data and recommendations [27]. To that point, the data analyzed for this set of guidelines has been collected through October 31, 2018. It is estimated that the new literature related to this guideline will be reviewed in approximately five years with written updates of the content and recommendations if indicated. 


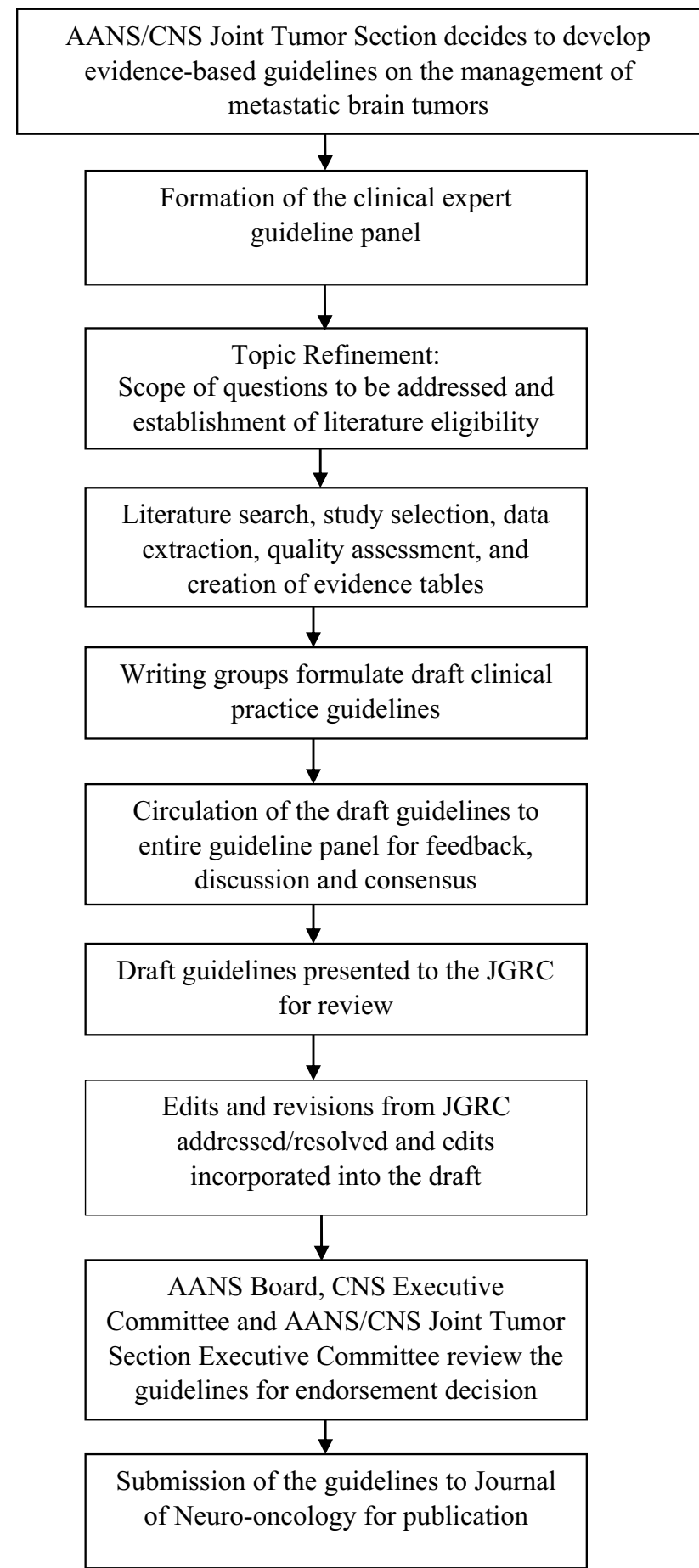

Fig. 1 Outline of the key steps in the process of developing these clinical practice guidelines

Acknowledgements The guidelines task force would like to acknowledge the Congress of Neurological Surgeons Guidelines Committee for their contributions through the initial development of the guideline and the American Association of Neurological Surgeons/Congress of Neurological Surgeons Joint Guidelines Review Committee for their review, comments, and suggestions throughout peer review.
Throughout the review process the reviewers and authors were blinded from one another. At this time the guidelines task force would like to acknowledge the following individual peer reviewers for their contributions: John O’Toole, MD, David Bauer, MD, Kimon Bekelis, MD, Andrew Carlson, MD, Isabelle Germano, MD, Catherine McClung Smith, MD, and Jonathan Sherman, MD.

\section{Compliance with ethical standards}

Conflict of interests The authors of this set of guidelines were required to report all possible COIs prior to beginning work on the guideline; including potential COIs that are unrelated to the topic of the guideline. The senior authors and the CNS Guidelines Committee reviewed the disclosures and either approved or disapproved the nomination. This was done in an ongoing basis and some initial writers were eventually withdrawn because of a change in conflict status. The senior authors and CNS Guidelines Committee were given latitude to approve nominations of members with possible conflicts and address this by restricting the writing and reviewing privileges of a given writer to topics unrelated to the possible COIs. Any costs related to these guidelines were funded exclusively by the Congress of Neurological Surgeons and the Section on Tumors of the Congress of Neurological Surgeons and the American Association of Neurological Surgeons. These organizations received no funding from any outside commercial sources to support the development of this document. Based on the conflict of interest disclosures the authors have no personal, financial, or institutional interest in any of the drugs, materials, or devices described in this article.

Disclaimer of liability This clinical systematic review and evidencebased guideline was developed by a multidisciplinary physician volunteer task force and serves as an educational tool designed to provide an accurate review of the subject matter covered. These guidelines are disseminated with the understanding that the recommendations by the authors and consultants who have collaborated in their development are not meant to replace the individualized care and treatment advice from a patient's physician(s). If medical advice or assistance is required, the services of a competent physician should be sought. The proposals contained in these guidelines may not be suitable for use in all circumstances. The choice to implement any particular recommendation contained in these guidelines must be made by a managing physician in light of the situation in each particular patient and based on existing resources.

\section{References}

1. Olson JJ, Ryken TC (2008) Guidelines for the treatment of newly diagnosed glioblastoma: introduction. J Neurooncol 89:255-258. https://doi.org/10.1007/s11060-008-9595-4

2. Mukundan S, Holder CA, Olson JJ (2008) Neuroradiological assessment of newly diagnosed glioblastoma. J Neurooncol 89:259-269. https://doi.org/10.1007/s11060-008-9616-3

3. Ryken TC, Frankel B, Julien T, Olson JJ (2008) Surgical management of newly diagnosed glioblastoma in adults: role of cytoreductive surgery. J Neurooncol 89:271-286. https://doi. org/10.1007/s11060-008-9614-5

4. Brat DJ, Prayson RA, Ryken TC, Olson JJ (2008) Diagnosis of malignant glioma: role of neuropathology. J Neurooncol 89:287311. https://doi.org/10.1007/s11060-008-9618-1

5. Buatti J, Ryken R, Smith MC, Sneed P, Suh J, Mehta M, Olson JJ (2008) Radiation therapy of pathologically confirmed newly 
diagnosed glioblastoma in adults. J Neuro-Oncol 89:313-337. https://doi.org/10.1007/s11060-008-9617-2

6. Fadul CE, Wen PY, Kim L, Olson JJ (2008) Cytotoxic chemotherapeutic management of newly diagnosed glioblastoma multiforme. J Neuro-Oncol 89:339-357. https://doi.org/10.1007/s1106 0-008-9615-4

7. Ostrom QT, Bauchet L, Davis FG et al (2004) The epidemiology of glioma in adults: a "state of the science" review. Neuro Oncol 16:1548-1563. https://doi.org/10.1093/neuonc/nou087

8. Nayak L, Reardon DA (2017) High-grade gliomas (2017) CONTINUUM: lifelong learning. Neurology 23:1548-1563. https:// doi.org/10.1212/01.con.0000464173.58262.d9

9. Rouse C, Gittleman H, Ostrom QT et al (2016) Years of potential life lost for brain and CNS tumors relative to other cancers in adults in the United States. Neuro-oncol 18:70-77. https://doi. org/10.1093/neuonc/nov249

10. Harrison RA, de Groot JF (2017) Cell signaling pathways in brain tumors. Top Magn Reson Imaging 26:15-26. https://doi. org/10.1097/RMR.0000000000000112

11. Krauze AV, Myrehaug SD, Chang MG et al (2015) A phase 2 study of concurrent radiation therapy, temozolomide, and the histone deacetylase inhibitor valproic acid for patients with glioblastoma. Int J Radiat Oncol Biol Phys 92:986-992. https://doi. org/10.1016/j.ijrobp.2015.04.038

12. Stupp R, Mason WP, van den Bent MJ et al (2005) Radiotherapy plus concomitant and adjuvant temozolomide for glioblastoma. $\mathrm{N}$ Engl J Med 352:987-996. https://doi.org/10.1056/nejmoa043330

13. Hassan A, Mosley J, Singh S, Zinn PO (2017) A comprehensive review of genomics and noncoding RNA in gliomas. Top Magn Reson Imaging 26:3-14. https://doi.org/10.1038/nature07385

14. Cancer Genome Atlas Research Network (2008) Comprehensive genomic characterization defines human glioblastoma genes and core pathways. Nature 455:1061-1068. https://doi.org/10.1038/ nature 07385

15. Berens ME, Giese A (1999) “..those left behind'.' Biology and oncology of invasive glioma cells. Neoplasia 1:208-219. https:// doi.org/10.1038/sj.neo.7900034

16. Verhaak RG, Hoadley KA, Purdom E et al (2010) Integrated genomic analysis identifies clinically relevant subtypes of glioblastoma characterized by abnormalities in PDGFRA, IDH1, EGFR, and NF1. Cancer Cell 17:98-110. https://doi. org/10.1016/j.ccr.2009.12.020

17. Weller M, Stupp R, Hegi ME et al (2012) Personalized care in neuro-oncology coming of age: why we need MGMT and 1p/19q testing for malignant glioma patients in clinical practice. Neuro Oncol 14(suppl 4):iv100-iv108. https://doi.org/10.1093/neuonc/ nos206
18. Louis DN, Perry A, Reifenberger G et al (2016) The 2016 World Health Organization classification of tumors of the central nervous system: a summary. Acta Neuropathol 131:803-820. https://doi. org/10.1007/s00401-016-1545-1

19. Stupp R, Taillibert S, Kanner AA et al (2015) Maintenance therapy with tumor-treating fields plus temozolomide vs temozolomide alone for glioblastoma: a randomized clinical trial. JAMA 314:2535-2543. https://doi.org/10.1001/jama.2015.16669

20. Kim MM, Umemura Y, Leung D (2018) Bevacizumab and glioblastoma. Past, present, and future directions. Cancer J 24:180 186. https://doi.org/10.1097/ppo.0000000000000326

21. Gerstner ER, Emblem KE, Sorensen GA (2015) Vascular magnetic resonance imaging in brain tumors during antiangiogenic therapy-are we there yet? Cancer J 21:337-342. https://doi. org/10.1097/ppo.0000000000000128

22. Brown CE, Alizadeh D, Starr R et al (2016) Regression of glioblastoma after chimeric antigen receptor T-cell therapy. N Engl J Med 375(26):2561-2569. https://doi.org/10.1056/NEJMoa1610 497

23. Neagu MR, Reardon DA (2015) An update on the role of immunotherapy and vaccine strategies for primary brain tumors. Curr Treat Options Oncol 16(11):54. https://doi.org/10.1007/s1186 4-015-0371-3.

24. Reznik E, Smith AW, Taube S, Mann J, Yondorf MZ, Parashar B, Wernicke AG (2018) Radiation and immunotherapy in high-grade gliomas. Where do we stand? Am J Clin Oncol 41:197-212. https ://doi.org/10.1097/coc.0000000000000406

25. Weiss T, Weller M, Roth P (2015) Immunotherapy for glioblastoma: concepts and challenges. Curr Opin Neurol 28:639-646. https://doi.org/10.1097/wco.0000000000000249

26. Moher D, Liberati A, Tetzlaff J, Altman DG (2009) The PRISMA group: preferred reporting items for systematic reviews and metaanalyses: the PRISMA statement. J Clin Epidemiol 62:10061012. https://doi.org/10.1016/j.jclinepi.2009.06.005

27. Clinical Guidelines We Can Trust (2011). National Academies Press, March 23, 2011. https://nationalacademies.org/hmd/repor ts/2011/clinical-practice-guidelines-we-can-trust.aspx. Accessed July 1, 2020.

Publisher's Note Springer Nature remains neutral with regard to jurisdictional claims in published maps and institutional affiliations. 